\title{
A Correlational Study on Mindset, Grit, and Adversity Quotient of Pre-Service Teachers: Evidence in Philippines and Hongkong
}

\author{
Alberto D. Yazon', Karen Ang-Manaig2, Ting Wai Ching Adrian ${ }^{3}$ \\ ${ }^{1,2}$ College of Teacher Education, Laguna State Polytechnic University, Philippines \\ 3 The Hong Kong Polytechnic University, Hong Kong
}

\begin{abstract}
Understanding pre-service teachers' mindset, grit, and adversity quotient boosts their morale, confidence, and self-esteem as future educators. This descriptive-correlational research determined the relationship between the aforementioned constructs of pre-service teachers in the Philippines and Hong Kong. The respondents of the study were 155 pre-service teachers from two Asian countries. The data were gathered through answering an online questionnaire generated through Google forms and disseminated through e-Mail and messenger on social networking sites. The responses from the respondents were automatically stored at the Google drive application. The standardized questionnaires were used in the study. The respondent's mindset was assessed using Dweck's Mindset Instrument (DMI). In terms of grit, it was measured using Duckworth's Grit-Short Scale, and the respondent's adversity quotient was examined using The Adversity Quotient Profile ${ }^{\circledR}$ 9.1 by Dr. Paul G. Stoltz. The majority of the pre-service teachers in the two Asian countries are dominated by female students with an ideal age bracket suited as university students possessing a growth mindset. Students with a growth mindset have displayed a higher level of grit and adversity quotients than those students with a fixed mindset. This study concluded that mindset and adversity quotient is significantly associated. Hence, stakeholders involved in the development of 21st-century learners should promote the mindset, but they may also develop other essential parallel variables, such as the adversity quotient, to encourage them to be desirable attribution necessary for being global and competitive citizens of the society.
\end{abstract}

Keywords: Self-determination, Growth Mindset, Grit, Adversity Quotient

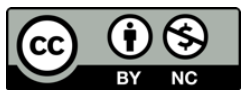

This is an open access article under the CC-BY-NC license.

\section{INTRODUCTION}

Dweck created a growth mindset that views learning as a continuous process; intelligence and skills are not predetermined but can be cultivated through hard work and appropriate training. It focuses on the plasticity and neuroplasticity of the brain "reconnecting" throughout life. Like muscles, the nerve connections in the brain grow with use and weaken when not challenged. It is important to be clear about the growth mentality in teaching because it can help students understand that hard work brings learning and skills that improve with practice. The growth mindset empowers students because mastery is based on hard work, not innate intelligence (Keesey, Shaefer, Joy \& Allen, 2018, cited Dweck, 2006).

Mindsets have made important discoveries in the field of intelligence. They showed that believing in their own abilities can affect school performance and other aspects of intelligence (KL Blackwell, Trzesniewski and Dweck, 2007; Blackwell, 2000; Dweck, 1986, as cited by Bond, 2017). An established method for studying mindset is to measure the participants' two sets of beliefs: an incremental mindset (often called growth beliefs) and an entity mindset (often called fixed beliefs). Progressive belief indicates the belief that a given mental structure is plastic and can be developed through practice. Entity belief requires people to believe that a trait is fixed or innate, with little or no possibility of improving a given ability (Dweck, 1986; O'Connor et al., 2013; Yager \& Dweck, 2012).

Corresponding author

albertyazon@lspu.edu.ph; karen.manaig@lspu.com; adrianwting@gmail.com DOI: https://doi.org/10.31098/ijmesh.v4i2.784 
International Journal of Management, Entrepreneurship, Social Science and Humanities (IJMESH), Vol. 4 (2), 174-181 A Correlational Study on Mindset, Grit, and Adversity Quotient of Pre-Service Teachers: Evidence in Philippines and Hongkong

Alberto D. Yazon; Karen Ang-Manaig; Ting Wai Ching Adrian

Mindset affects a person's overall performance (Blackwell, 2000; Yeager \& Dweck, 2012). People with a fixed mindset see their mistakes as a lack of competence, often disconnecting from current tasks, leading to poor performance, such as in academic activities (Bond, 2017). People with a sense of growth are more able to cheer up after making mistakes, thereby improving performance skills. This may also be due to the fact that those with a progressive mentality are more convinced of the positive effects of hard work. In problem-solving tasks, the mentality has an important effect on cognition and has different effects on the brain (Dweck, Chiu, \& Hong, 1995; Blackwell, 2000). People with a growth mindset focus on their mistakes and show increased brain activity after making them, assuming they are the ones trying to learn and improve on a given task (Schroder, Moran, Donnellan \& Moser, 2014, Bond, cited in 2017).

Having a growth mindset helps students achieve excellent results in school, which in turn helps them escape poverty (Card, 2001). For example, compared to students with a fixed mindset, students with a growth mindset prefer school, take on more challenging tasks, learn more, and earn better grades (Aronson, Fried, \& Good, 2002; Blackwell, Trzesniewski, \& Dweck, 2007; Romero et al., 2014).

Grit was defined as the passion for long-term goals and trait-level perseverance by Angela Duckworth (Duckworth et al., 2007, Chang, 2014 cited). Some statements that describe more persistent students include behaviors such as not being discouraged by setbacks, staying focused on the project, working hard, completing assignments, and diligently. In contrast, statements that describe less resilient students include behaviors such as being distracted by new ideas and projects, setting goals but choosing different goals later, and having difficulty staying focused on long-term projects.

The concept of growth mindset has recently been incorporated into the concept of GRIT. Grit is defined as a combination of passion and perseverance (Duckworth,2016). These attributes of GRIT can be achieved through (a) cultivating an "attitude of gratitude", (b) keeping goals in mind, (c) practicing a growth mentality, (d) finding other people with the same characteristics, and (e)) in their influence Create value culture within the circle (Duckworth, 2016). Similar to mentality growth, courage can be cultivated; growth mentality and value are interrelated personalities. The growth mindset promotes a positive attitude and willingness to try; because through hard work, everything is possible. Cultivate the courage to enable students to persevere, even in adversity, and persevere until the goal is achieved.

The GRIT is an active psychology building, and it can be defined as trait-level perseverance and interest consistency (Duckworth, Peterson, Matthews, \& Kelly, 2007). Duckworth et al. (2007) mention that to overcome challenges, you need to work strenuously, maintain efforts, interest over the years despite failures, setbacks, and plateaus in progress. Duckworth et al. (2007) introduced the construct considering the history of research to investigate related indicators for personal success. The ability of biography information, patience, zeal, and the integration of objectives seems important to achieve in addition to talent and intelligence (COX, 1926, 1892, Turnman \& Oden, 1947). Duckworth et al. (2007) identified these characteristics by introducing the concepts that touch these characteristics and are reduced to two dimensions. The effort of patience and consistency of interest. The process to achieve specific levels of competence, intentional exercise, and initial failure can take several months or even more years, but it is necessary to suppress the initial interest (Schimdt et al., 2015).

As per Stoltz (1997), Adversity Quotient ${ }^{\circledR}$ or otherwise called "AQ®" is the study of strength. It depicts how well one withstands difficulty and one's capacity to beat it. Moreover, it predicts who will defeat misfortune and who will be squashed, who will surpass assumptions and who will miss the mark, who surrenders, and who dangers (Daloos, 2015). Stoltz (1997) further clarified AQ ${ }^{\circledR}$ into four measurements as $\mathrm{C}$ - Control. This is the capacity to control one's reaction to whatever could occur. Individuals with higher $A Q \circledR$ are bound to show a predominant type of reaction control. These individuals can deal with their reactions when difficulty strikes (Stoltz, 1997). 0 - Origin and Ownership. The principal 0 is the 
International Journal of Management, Entrepreneurship, Social Science and Humanities (IJMESH), Vol. 4 (2), $174-181$ A Correlational Study on Mindset, Grit, and Adversity Quotient of Pre-Service Teachers: Evidence in Philippines and Hongkong

Alberto D. Yazon, Karen Ang-Manaig, Ting Wai Ching Adrian

degree to which an individual advances a circumstance within reach and takes it upon oneself. Those with higher $\mathrm{AQ} \otimes$ consider themselves responsible for managing circumstances paying little heed to their causes. Those with lower $A Q \circledR$ will, in general, fault themselves for awful circumstances. The other 0 relates to responsibility; it resembles possessing the results of misfortune. Those with higher AQ® assume the liability over the consequences of antagonistic circumstances, while those with lower AQ® surrender effectively and fault others (Stoltz, 1997). R - Reach. This measurement decides how an individual sees the issue to be. Those with higher $A Q \circledR$ bargain issues emphatically and not let them influence their lives. In any case, those with low $A Q \circledR$ are slanted to be poor in dynamic (Stoltz, 1997). E - Endurance. This idea identifies with how long an individual sees the affliction will last. Those with higher $A Q \circledR$ keep up with expectations and confidence. For those with low $A Q \circledR$, they consider themselves to be the reason for disappointment and, in this manner, may get themselves less inclined to By finding, estimating, and applying $A Q \circledR$, individuals can remain roused even in unfriendly circumstances. Impressive impulse in the investigation of $A Q \circledR$ came from crafted by Dr. Paul Stoltz. In light of various examinations, he fostered the AQ Profile $\AA$ and is credited as the most trustworthy instrument estimating $A Q \circledR$. From its origin, $A Q \circledR$ turns into the main device in estimating how successfully one arrangement with the affliction (Stoltz, 1997 as referred to by Daloos, 2015).

Based on the reviewed literature, it can be deduced that there is a need to conduct research that examines Mindset, GRIT, and Adversity of Quotient of 21st Century Pre-Service Teachers in the Philippines. Consequently, there is limited literature on the relationship between these constructs.

Understanding the influence of Mindset, Grit, and Adversity Quotient of Pre-Service Teachers in the Philippines has never been explored hence this study. Lastly, this research hopes to provide input to institutional policy on student development that will make future teachers be resilient in the teaching force.

\section{Objectives}

This study aimed to determine the relationship between mindset, grit, and adversity quotient of preservice teachers in the Philippines and Hongkong. Specifically, it sought to answer the following questions:

1. What is the profile of the respondents in terms of:
1.1 age
$1.2 \mathrm{sex}$
1.3 country

2. What is the level of the mindset of the respondents in terms of:

\section{1 fixed mindset}

2.2 growth mindset

3. What is the grit level of the respondents in terms of:

3.1 consistency of interest and

3.2 persistence of effort?

4. What is the level of adversity quotient of respondents in terms of

4.1 core

4.2 origin

4.3 reach

4.4 endurance

5. Is there a significant relationship between a student's mindset and grit? 
International Journal of Management, Entrepreneurship, Social Science and Humanities (IJMESH), Vol. 4 (2), 174-181

A Correlational Study on Mindset, Grit, and Adversity Quotient of Pre-Service Teachers: Evidence in Philippines and Hongkong

Alberto D. Yazon; Karen Ang-Manaig; Ting Wai Ching Adrian

6. Is there a significant relationship between a student's mindset and adversity quotient?

7. Is there a significant relationship between students' grit and adversity quotient?

\section{RESEARCH METHODS}

This study used the descriptive-correlational research design. This design is appropriate in describing the characteristics of a large population (Wyse,2012).

The respondents of the study were the 155 pre-service teachers from Hongkong and the Philippines. The data were gathered through answering an online questionnaire to be generated through Google forms and disseminated through E-Mail and Messenger of Social Networking Sites. The responses from the respondents were automatically stored at the Google drive application.

This study uses standardized questionnaires. The Dweck Mindset Tool (DMI) was used to measure the mindset of the interviewees. The tool assesses students' perceptions of their own intelligence on 16 separate project statements, ranking between 16 points. The scale consists of the following scores: 1 (strongly agree), 2 (agree), 3 (in most cases) agree), 4 (mostly disagree), 5 (disagree), and 6 (strongly disagree). Respondents were asked to read the 16 project statements and use the scale numbers above to rate the degree of agreement or disagreement with the projects. The incremental items were "reversed" so that strongly disagreeing with an entity item is similar to strongly agreeing with the incremental item.

In terms of statements of fixed items, the questionnaire contains statements numbers $1,2,4,6,9,10,12$, and 14. These statements involve constant and fixed factors of talent and intelligence. The incremental elements of the questionnaire consist of $3,5,7,8,11,13,15$, and 16. There are four incremental elements and four fixed elements, which focus on the intelligence of the students. Similarly, there are four incremental items and four fixed item statements, emphasizing the development of student talent. In the incremental item statement, student-chosen scores describe intelligence and talents as things that can be changed and are reversed ( 1 becomes 6,2 becomes 5,3 becomes 4, 4 becomes at 3, 5 becomes 2, and 6 becomes 1). These scores are averaged with item statements that describe intelligence and talents as fixed and immutable factors

The Duckworth's Grit-Short Scale was utilized to assess the respondents' grit. It was an 8 item set to measure the trait-level of passion for long-term goals and perseverance using a 5-point Likert Scale. Moreover, to determine the level of adversity quotient of the respondents, The Adversity Quotient Profile ( 9.1 by Dr. Paul G. Stoltz was used. This instrument is a self-rating intended to measure the capacity of an individual to respond positively to problems through stimulating their hardwired pattern of response into a wide-ranging hostile event. There are four scales in AQ; namely, Control, Ownership, Reach, and Endurance. 
International Journal of Management, Entrepreneurship, Social Science and Humanities (IJMESH), Vol. 4 (2), 174-181 A Correlational Study on Mindset, Grit, and Adversity Quotient of Pre-Service Teachers: Evidence in Philippines and Hongkong

Alberto D. Yazon, Karen Ang-Manaig, Ting Wai Ching Adrian

RESULTS AND DISCUSSION

Table 1. Profile of the respondents in terms of country of origin, age, and sex

\begin{tabular}{|c|c|c|c|c|c|}
\hline \multicolumn{6}{|c|}{ Age Group * Country * Sex Crosstabulation } \\
\hline \multirow[b]{2}{*}{ Sex } & & & \multicolumn{2}{|c|}{ Country } & \multirow[b]{2}{*}{ Total } \\
\hline & & & Hong Kong & Philippines & \\
\hline \multirow{3}{*}{ Female } & \multirow{2}{*}{ Age Group } & 18-21 years old & 6 & 63 & 69 \\
\hline & & above 21 years & 7 & 22 & 29 \\
\hline & \multirow{4}{*}{ Age Group } & Total & 13 & 85 & 98 \\
\hline \multirow{3}{*}{ Male } & & 18-21 years old & 1 & 41 & 42 \\
\hline & & above 21 years & 1 & 14 & 15 \\
\hline & & Total & 2 & 55 & 57 \\
\hline \multirow{4}{*}{ Total } & \multirow{4}{*}{ Age Group } & 18-21 years old & 7 & 104 & 111 \\
\hline & & above 21 years & 8 & 36 & 44 \\
\hline & & \multirow{2}{*}{ Total } & 15 & 140 & 155 \\
\hline & & & $9.7 \%$ & $90.3 \%$ & $100.0 \%$ \\
\hline
\end{tabular}

As shown in Table 1, there are 15 (9.7\%) respondents from Hongkong, seven (7) of which are $18-21$ years old and eight (8) are above 21 . Two out of 15 are male, while 13 are female.

One hundred forty (140) or ninety and three-tenths percent $(90.3 \%)$ of the total respondents are from the Philippines, 85 of which are female and 55 are male. Of this number, 104 have ages that range from $18-21$, and the remaining 36 respondents are above 21 years old.

It can be inferred from Table 1 that majority of the pre-service teachers in the two Asian countries are dominated by female students with an ideal age bracket suited as university students.

Table 2. The mindset of the $21^{\text {st }}$ century pre-service teachers

\begin{tabular}{ccc}
\hline Mindset & Frequency & Percent \\
\hline \hline Fixed & 44 & 28.4 \\
Growth & 111 & 71.6 \\
\hline \hline Total & 155 & 100.0 \\
\hline
\end{tabular}

It is presented in Table 2 that majority of the $21^{\text {st }}$ pre-service teachers portray a growth mindset $(111$ or $71.6 \%)$ while $44(28.4 \%)$ are classified as with a fixed mindset.

In a fixed mindset, students think that their basic abilities, intelligence, and talents are just fixed characteristics. They have a certain number, nothing more, and then their goal becomes to always look smart and never look unwise. In a growth mindset, students understand that their talents and abilities can be developed through hard work, good teaching, and perseverance. They do not necessarily believe that everyone is the same or that anyone can become Einstein, but they believe that everyone will become smarter as long as they work hard (Dweck, 2020).

In addition, Dweck asserts that the concept of a growth mindset is a way of thinking about someone, feeling, and action, while a fixed mindset creates an individual into non-learners. All of it contributes to 
International Journal of Management, Entrepreneurship, Social Science and Humanities (IJMESH), Vol. 4 (2), 174-181

A Correlational Study on Mindset, Grit, and Adversity Quotient of Pre-Service Teachers: Evidence in Philippines and Hongkong

Alberto D. Yazon; Karen Ang-Manaig; Ting Wai Ching Adrian

the learning, improvement, and well-being of an individual. A growth mindset stimulates the ability to focus, determine, work and accept the ability to accept failures.

In honing the $21^{\text {st }}$-century skills of the learners, teachers faced different adversities in teaching. Thus, the students' great malleability of the brain deals with its capacity to change, grow and even reorganize during the learning process. The idea of creating the idea of removing the steps of your comfort zone to form a new connection makes your own ability develop.

Table 3. Grit level of $21^{\text {st }}$ century pre-service teachers categorized with fixed and growth mindset in terms of perseverance

\section{Indicative Statement}

Fixed Growth

1. Setbacks don't discourage me. I don't give up easily.

$(\mathrm{N}=44)$

$(\mathrm{N}=111)$

2. I am a hard worker.

3.82

4.12

3. I finish whatever I begin.

4.11

4.05

4. I am diligent. I never give up.

4.07

4.06

Composite

4.16

4.27

4.04

4.13

Legend: $4.50-5.00=$ Very High; 3.50-4.49 = High; $2.50-3.49=$ Average $1.50-2.49=$ Low $1.00-1.49=$ Very Low

Based on the results in Table 3, both groups of pre-service teachers have a comparable level of persistence which is "high". It can be observed that there is a slight mean difference of .09 in terms of their composite score, indicating that students with a growth mindset have displayed a higher level of perseverance than those students with a fixed mindset.

Table 4. Grit level of $21^{\text {st }}$ century pre-service teachers categorized with fixed and growth mindset in terms of interest

\begin{tabular}{llcc}
\hline \multicolumn{1}{c}{ Indicative Statement } & $\begin{array}{c}\text { Fixed } \\
(\mathrm{N}=44)\end{array}$ & $\begin{array}{c}\text { Growth } \\
(\mathrm{N}=111)\end{array}$ \\
\hline \hline 1. & New ideas and projects sometimes distract me from previous & 3.11 & 3.17 \\
ones. & 3.14 & 3.15 \\
2. I have been obsessed with a certain idea or project for a short & 2.84 & 3.09 \\
$\quad \begin{array}{l}\text { time but later lost interest. } \\
\text { 3. I often set a goal but later choose to pursue a different one. }\end{array}$ & 2.84 & 2.95 \\
\hline $\begin{array}{l}\text { I have difficulty maintaining my focus on projects that take more } \\
\text { than a few months to complete. }\end{array}$ & 2.98 & 3.09 \\
\hline
\end{tabular}

Legend: $4.50-5.00=$ Very Low; 3.50-4.49 = Low; 2.50-3.49 = Average; $1.50-2.49=$ High; 1.00-1.49 = Very High

Table 4 reveals that both groups of pre-service teachers have an almost comparable level of interest which is "average". It can be observed that there is a slight mean difference of .09 in terms of their composite score, indicating that students with a fixed mindset have exhibited a higher level of interest than those students with a fixed mindset. 
International Journal of Management, Entrepreneurship, Social Science and Humanities (IJMESH), Vol. 4 (2), $174-181$ A Correlational Study on Mindset, Grit, and Adversity Quotient of Pre-Service Teachers: Evidence in Philippines and Hongkong

Alberto D. Yazon, Karen Ang-Manaig, Ting Wai Ching Adrian

Table 5. Adversity Quotient level of $21^{\text {st }}$ century pre-service teachers categorized with fixed and growth mindset in terms of control, ownership, reach, and endurance

\begin{tabular}{lcccccc}
\hline \multirow{2}{*}{ AQ } & \multicolumn{3}{c}{ High } & \multicolumn{2}{c}{ Average } & \multicolumn{2}{c}{ Low } \\
\cline { 2 - 7 } \multicolumn{1}{c}{ Dimensions } & Growth & Fixed & Growth & Fixed & Growth & Fixed \\
\hline \hline Control & $20 \%$ & $19 \%$ & $50 \%$ & $52 \%$ & $30 \%$ & $29 \%$ \\
Ownership & $16 \%$ & $15 \%$ & $66 \%$ & $50 \%$ & $18 \%$ & $35 \%$ \\
Reach & $30 \%$ & $15 \%$ & $27 \%$ & $36 \%$ & $43 \%$ & $49 \%$ \\
Endurance & $34 \%$ & $23 \%$ & $50 \%$ & $43 \%$ & $16 \%$ & $33 \%$ \\
\hline
\end{tabular}

Fixed $(N=44) ;$ Growth $(N=111$

Generally, it can be gleaned from Table 5 that students with a growth mindset have a higher level of control, ownership, reach, and endurance compared to those pre-service teachers with a growth mindset.

Table 6. Test of the significant relationship between mindset, grit, and adversity quotient

\begin{tabular}{|c|c|c|}
\hline Variables & $\mathbf{X}^{2}$ & df \\
\hline Mindset and Grit & 2.620 & 3 \\
\hline Mindset and AQ & $6.884^{*}$ & 2 \\
\hline Grit and AQ & 7.290 & 6 \\
\hline
\end{tabular}

*Significant at .05 level

Table 6 reveals that there is a significant relationship between mindset and adversity quotient of $21^{\text {st }}$ century pre-service teachers $\left[\mathrm{X}^{2}(2)=2.620 ; \mathrm{p}<.05\right]$.

Stolz (2019) stated that the reality of today's high-speed business economy requires greater capacity, speed, and capabilities of an individual. And everyone faces difficulty. The difference is How do people deal with it. Thus, in dealing with uncertainty or difficulty, a person's mentality improves one's inner self. Students with a growth mindset will never stop learning and growing. They work tirelessly to pursue their lifetime goals. They inspire others to see their full potential. Regardless of their position in work or life, they have goals and enthusiasm for what they do.

\section{CONCLUSION AND RECOMMENDATIONS}

This study concluded that mindset and adversity quotient is significantly associated. Hence, the following may be considered:

1. Stakeholders involved in the development of students in the 21st century must not only improve their way of thinking but also develop other important parallel- variables, such as adversity quotients, to encourage them to become the ideal attribution required for global citizens and social competitiveness.

2. The university, through the Office of Student Affairs and Services, may consider a studentdevelopment plan of activities that will enhance students' own skills and abilities and selfawareness.

3. Teachers may be curious about their teaching and commit to providing lifelong learning to the students. Try to empathize and sympathize with the individual needs of the learners.

4. Students may get resilient in facing challenges. Knowing that if you want to achieve something worthwhile, you will face many challenges along the way, be prepared for these challenges, and, at times, be prepared for failure.

5. Pre-service teachers may continue to do what they like to do and love what they do since success is much easier when you are passionate about what you are doing, whether you have done it yourself. It is important to cultivate a passion for things or to focus on doing what you like to do. Being tenacious takes a lot of work to be successful, but it takes more than hard work - you have to be persistent, overcome obstacles, and get back on your feet after every fall. 
International Journal of Management, Entrepreneurship, Social Science and Humanities (IJMESH), Vol. 4 (2), 174-181

A Correlational Study on Mindset, Grit, and Adversity Quotient of Pre-Service Teachers: Evidence in Philippines and Hongkong

Alberto D. Yazon; Karen Ang-Manaig; Ting Wai Ching Adrian

6. The parallel study may be conducted by future researchers, including other variables not explored in this study in a larger population.

\section{REFERENCES}

Bond, R. (2017) Creativity and Mindset. Carleton University. Retrieved from https://carleton.ca/ics/wp-content/uploads/RyanBondThesisFinal.pdf Froedge, K.L. (2017) The Effect of a Growth Mindset on Student Achievement Among Students with Disability. Retrieved from: https://digitalcommons.wku.edu/cgi/viewcontent.cgi?article=1118\&context=diss

Chang, W. (2014) GRIT and Academic Performance: Is Being Grittier Better?
University
of
Miami.
Retrieved
from https://scholarlyrepository.miami.edu/cgi/viewcontent.cgi?article=2319\&context=oa_dissertat ions

Daloos, M.J. (2015) Emotional Intelligence and Adversity Quotient of Selected

Helping Professionals. Peak Learning Inc. Retrieved from: https://www.peaklearning.com/wpcontent/uploads/2019/05/PEAK_GRI_daloos.pdf

Keesey, S., Schaefer, A., Loy, M., and Allen, C.J. (2018) Developing Growth

Mindset and GRIT in Preservice Teachers. Kentucky Teacher Education Journal: The Journal of the Teacher Education Division of the Kentucky Council for Exceptional Children: Vol. 5 : Iss. 1, Article 3. Retrieved from :https://digitalcommons.murraystate.edu/ktej/vol5/iss1/3

Mahmud, A. (n.d.) Understanding Dweck's Mindset Theory. Retrieved from: http://mindsets.port.ac.uk/?p=80

Schimdt, F.T., Fleckenstein, J., Retelsdorf, J., Eskreis-Winkler, L. \& Moller, J. (2015) A German Validation and a Domain-Specific Approach to Grit. European Journal of Psychological Assessment (2019), 35, pp. 436-447. https://doi.org/10.1027/1015-5759/a000407 